Article

\title{
Sustainability and Stakeholder Awareness: A Case Study of a Scottish University
}

\author{
Abdulhakeem Raji (1D) and Abeer Hassan* \\ School of Business and Creative Industries, Paisley Campus, University of West of Scotland Paisley, \\ Paisley PA1 2BE, UK; abdulhakeem.raji@uws.ac.uk \\ * Correspondence: Abeer.hassan@uws.ac.uk
}

Citation: Raji, A.; Hassan, A. Sustainability and Stakeholder Awareness: A Case Study of a Scottish University. Sustainability 2021, 13, 4186. https://doi.org/ $10.3390 /$ su13084186

Academic Editors: Benedetta Siboni and Jordi Colomer Feliu

Received: 13 December 2020

Accepted: 10 March 2021

Published: 9 April 2021

Publisher's Note: MDPI stays neutral with regard to jurisdictional claims in published maps and institutional affiliations.

Copyright: (c) 2021 by the authors. Licensee MDPI, Basel, Switzerland. This article is an open access article distributed under the terms and conditions of the Creative Commons Attribution (CC BY) license (https:// creativecommons.org/licenses/by/ $4.0 /)$.

\begin{abstract}
This paper adopted a case study approach to investigate the sustainability practices of a Scottish university in order to understand if sustainability forms part of its central policy agenda. As such, the paper focuses on the levels of awareness and disclosure of their sustainable practices, measuring the impacts and effectiveness of those initiatives. This paper introduces signaling theory to explore the idea that appropriate communication via integrated thinking can close the gap between the organization and its stakeholders. We believe that the provision of this relevant information will lead to better communication between the organization and its stakeholders, supporting a signaling theory interpretation. Therefore, we are suggesting that integrated thinking is an internal process that organizations can follow to increase the level of disclosure as a communication tool with stakeholders. From the literature reviewed, four themes were identified (definition of university sustainability, sustainability awareness, disclosure framework within universities, and level of accountability). The research adopted a pragmatic view and conducted individual interviews with participants belonging to three stakeholder groups (members of the university's senior management, the governing council, and the student union executive). Although this study focused on just one Scottish university, it should still provide some insight for the better understanding of the underpinning issues surrounding the sustainability accountability practices of Scottish universities in general. The research findings indicated that the university prioritized only two sustainability dimensions - economic and environmental — and that the university still perceived sustainability as a voluntary exercise. Additionally, it is evident that the university had no framework in place for measuring its sustainability delivery-and therefore had no established medium of communicating these activities to its stakeholders. Moreover, research findings showed that the social and educational context of sustainability was lacking at the university. The university has done little or nothing to educate its stakeholders on sustainability.
\end{abstract}

Keywords: sustainability; disclosure; awareness; accounting framework

\section{Introduction}

"Institutions of higher education have a significant role in promoting change to sustainable development models as centers of knowledge and innovation" [1]. However, due to the level of competition amongst universities to grow their market shares, various methods have been adopted by specific universities to present themselves as green institutions [2], even though universities have been at the forefront of confronting the sustainability challenges plaguing communities around the world [3,4]. It is therefore of concern that these institutions of higher learning have not led by example [5], as sustainability practices are quite new amongst universities [2]. Even as such, some researchers believe that the emergence of a so-called green revolution is nothing but greenwashing [2]; that is, a simple representation on paper. This study will therefore endeavor to analyze and contribute mildly to such a problem-based research area by contextualizing the accountability perspective. 
Universities are often criticized for using sustainability to attract wider future investment, retain competitive advantages, and maintain good public standing [6,7]. McWilliams and Siegel [8] opined that the demand for sustainability, as integral to corporate strategy, is likely to be driven by several stakeholder groups, including investors, consumers, employees, and the community. Analyzed in terms of costs and benefits, a case for sustainability can be based on a differentiation strategy and translated into a competitive advantage for an institution [9].

As such, universities today have seen the link between sustainability and growth-but with some inconsistency [10]. However, it can be argued that sustainability will be a strong basis for businesses' existence in the very near future [11]. It is alarming to note, therefore, that even at the bedrock of knowledge itself, the stakeholders (students and staff) do not pay attention to the green culture of the universities, let alone demand its delivery [5,7]. Despite the propensity for enhanced debate on sustainable growth, the absence of adequate university guidance does not promote the evolution of discourse on this topic in the field of higher education [12].

Based on the above discussion, the study aimed at investigating the state of sustainability from the perspective of a Scottish university. To achieve this aim, a number of objectives were established: (1) determine the position of the university on sustainability; (2) ascertain the level of disclosure and overall awareness of sustainable practices by the university to its stakeholders; and (3) investigate the level of accountability. Our justification for this study was an intent to improve the level of disclosure on sustainability activities in the higher education sector to enhance stakeholders' engagement and trust. The main motivation for this study was that higher education has its own specific challenges-including international competition, student recruitment, research funding, and student expectations-that make the connections and interdependence between its departments through integrated thinking crucial to provide relevant information to stakeholders on value creation [13]. The provision of this relevant information should lead to better communication between the organization and its stakeholders, supporting a signaling theory interpretation [14]. Therefore, we are suggesting that integrated thinking is an internal process that organizations can follow to increase the level of disclosure as a communication tool with stakeholders.

\section{University Sustainability}

Universities have been in existence for centuries as the bedrock of education and the development of human sustainability [15]; however, not much has been done by universities to adopt sustainable practices [16]. The changes and challenges faced by universities in the adoption of sustainability in their operations and delivery has been a major area of research interest in recent times due to the mass expansion, internationalization, diversification, and commercialization of higher education institutions around the world [17,18]. Given that universities are often seen as institutions not established for business purposes, they often neglect sustainability as a practice-although some universities have tried to include it in their policy statement [19].

A study by Wright [20] examined the role of universities in achieving a sustainable future, key issues facing these universities, and the barriers to implementing sustainability initiatives on campus [20]. The research findings showed that, although a majority of the participants were well-versed in the concept of sustainable development, they were less familiar with the concept of sustainable university systems [20]. However, as [2] identified, a majority of them were dedicated to having their university attain the top position in the sustainable universities league table. The participants also listed financial predicaments, lack of understanding and awareness of sustainability issues amongst the university population, and resistance to change as the main barriers in the path toward sustainability [20]. Jones [2], in his research into the university sustainability league tables averred that "while many universities espouse non-technocratic, pluralist engagement visions and aspirations, they simultaneously enact a predominantly modernist, technocratic, planned, top-down, bureaucratic approach to the process of organizational change" [2]. In contrast, however, 
a study by Nejati et al. [21] showed that the leading universities in the world have taken corporate social responsibility seriously [21]. Universities are no longer just institutions of higher education and research which grant academic degrees in a variety of subjects; rather, they are institutions which train responsible people and produce cutting edge knowledge that can help to solve issues and problems in society [21].

As universities are gaining more freedom to determine their own strategies and deliveries (due to declining central government funding) [22], diverse means of attaining funding goals are encouraged [23]. This autonomy has come at a cost as increasingly tight government regulations now review the performance and quality of the university-which must match the level of funding it receives from public funds, students, or businesses [24]. As such, universities are devising means to strengthen their market position while also meeting these regulatory criteria. These changes have seen external parties become members of the boards of universities as opposed to traditional academics. The changes in governance and expansive funding channels are arguably responsible for the rush by universities to be sustainability-driven at their core [25]. Some researchers have argued that these are simply strategies to access more corporate funding as opposed to attempts to truly deliver on sustainability.

\subsection{Accountability and Disclosure}

It is worth noting that disclosure of a company's sustainability activities is not generally mandatory; however, some organizations voluntarily provide such disclosures. According to Lozano [26], university sustainability is still at an early stage, given the level of accountability delivered thus far and the level of voluntary disclosure of universities in comparison to corporations. As such, agreed-upon guidelines or standards on how universities should report sustainability activities to their stakeholders is needed [19,27]. In this vein, a stream of prior studies adopted the Global Reporting Initiative (GRI) guidelines to carry out their content analyses. Lozano [28] investigated the state of sustainability reporting in 12 UK universities' sustainability reports. The results showed that universities tended to focus on economic and environmental dimensions in their sustainability reports. However, the level of disclosure on sustainability is lower in universities in comparison with corporations. Additionally, Hinson et al. [29] investigated 6 Ghanaian universities' sustainability reports. The findings provided evidence that sustainability performance reporting was based on the institutionalized demands of stakeholders. In an explanatory study, Vagnoni and Cavicchi [30] explored sustainable devolopment at 67 Italian public universities. They found that $91 \%$ of their sample had been engaged in sustainability activities. In addition, the study of Ntim et al. [31] pointed out that voluntary disclosures can be an efficient means of preserving credibility by gaining support from strong stakeholders-particularly in times of crisis, when the capacity of a university to ensure continued operation is at risk.

Based on the above discussion, it has been noted that university sustainability accountability is a voluntary activity, aimed at either communicating the sustainability initiatives of corporations to their stakeholders $[26,32,33]$ or the assessment of the economic, social, and environmental (Triple Bottom Line) activities of an organization [26]. Additionally, the current level of sustainability accounting by universities is seen as a charade, geared toward leap-frogging up the league tables [2] rather than due diligence. The dawn of the decade saw the adoption of sustainability accountability by large multinational corporations [32] via the publication of sustainability reports [26]. Although universities have adopted a different sustainability accounting framework as compared to corporate organizations [34], the absence of regulatory standards for sustainability initiatives at universities [20] have led to the emergence of various guidelines [26]. This is because some studies show low rates of assertions of sustainability; in reality, Bekessy et al. [35], Wright [5] and Filho [36] all averred that the stakeholders of universities are not usually involved in the conceptualization of sustainability initiatives and frameworks. Given the low success rate of these, "it is also worthy of note that many of the so-called "leading schools" in the area of accounting 
did not embrace research in areas associated with social and environmental accountabilities" [37]. Additionally, the recent study by Sepasi et al. [38] asserted that—growing concerns over issues of sustainability notwithstanding-higher education institutions have not actively adopted sustainability reporting practices, e.g., by publishing consistent and periodic reports and integrating reporting into their sustainability management.

Taking into account that communication is at the core of a university's function, we would expect that universities should integrate sustainability activities into their strategiesespecially as the positive publicity that universities enjoy as signatories to various declarations and policies often precedes the enaction of those policies [35]. This means that integrating sustainability into a university's core activities should provide positive signals to stakeholders.

\subsection{Sustainability Accounting Framework for Universities-The Use of Integrated Thinking}

Existing sustainability accounting practices have been largely influenced by the development of reporting guidelines [39]. Developing these guidelines and standards has proven to be very challenging, given the ambiguous nature of sustainability initiatives and the varied backgrounds of stakeholders in higher education [19].

It is very important to look at multidisciplinary activities in the higher education sector. "Universities have a unique place in society. They are not only centres of creative thinking and innovation but they also fulfil many additional roles, providing leadership, advice and support. As a result, academics and scientists are the nation's powerhouses of knowledge and are playing a critical role in the global response to the pandemic, informing decisionmaking through their expertise" [40]. For example: for any university to be able to offer excellent service for its customers (students), it would have to have excellent academics who are experts in their fields, excellent technology facilities, academic and pastoral support, professional staff, exam units, etc. A number of departments and divisions would have to work together to offer excellent service. According to Hassan et al. [41], there is growing adoption of an integrated thinking approach by universities regarding the reporting of their sustainability activities.

Integrated thinking is defined as "the reflection of connectivity and interdependencies between various factors which affect an organization's value creation capacity" [42]. The International Integrated Reporting Committee (IIRC) [43] asserts that integrated thinking supports integrated decision-making and actions-leading to short, medium, and longterm value creation by establishing an active relationship between different operating and functional units. However, of the various existing guidelines, the (GRI) standards are the most widely adopted, offering the best available options for sustainability accountability. This is because they reflect economic, social, and environmental dimensions [26], thus departing from environmentally prejudiced references to sustainability [44]. However, the Global Reporting Initiative (GRI) accounting standard was not developed for universities, as it does not contextualize the educational dimension of university sustainability [26,44]. Researchers have proposed that the Global Reporting Initiative (GRI) standard could be complemented and modified to include the core competencies of universities (especially the educational dimension) [26].

There is growing demand for accountability and transparency by investors and society regarding sustainability practices of universities $[12,45,46]$. As such, universities' accountability to their various stakeholders should allow them to properly engage with them and carry them along [21,37,47]. Lozano et al. [27] asserted that the implementation of accountability should incorporate outreach, assessment, and reporting of the various sustainable activities of the university. They further averred that there is a need for the conceptualization of a consensus guideline, framework, standard, and tool for accountability of university sustainability. Alonso-Almeida et al. [48] revealed that few universities are taking the initiative to properly document and communicate their sustainable engagements, thus justifying the Lozano [26] proposal for the adoption of the Graphical Assessment of Sustainability in Universities (GASU) as a more robust tool for holistic 
sustainability accounting. Lozano et al. [27] asserted that having a holistic perspective that addresses various interrelations in the dimensions, categories, and indicators of sustainability are necessary. The Graphical Assessment of Sustainability in Universities (GASU) 2006 standard was revised in 2011 to align with the Global Reporting Initiative (GRI) G3 as updated in 2011, in order to facilitate better and more holistic coverage of issues concerning sustainability and their interactions [27].

Therefore, this paper reinforces the importance of adopting a disclosure framework based on integrated thinking to enhance stakeholders' trust. Although universities are places of education, vessels for researchers, crucibles for innovators and receptacles for leadership, they are poor at communicating their contributions and value to wider society [49].

\subsection{Theoretical Framework}

It is clear from the above discussion that there is no universally adaptable accounting standard or framework for university sustainability $[5,26,27,36,48]$. Hence, there is a need for a theoretical proposition to further unravel the realities of the subject. Table 1 summarizes these themes.

Table 1. Emergent themes.

\begin{tabular}{cl}
\hline Themes & \multicolumn{1}{c}{ Related Issues } \\
\hline Theme 1 & $\begin{array}{l}\text { Sustainability is defined narrowly in the environmental context by universities. This } \\
\text { limits the delivery of sustainable development. } \\
\text { Source: Lozano [28]; Lozano et al. [27]; Alonso-Almeida et al. [48]; Nejati et al. [21] }\end{array}$ \\
\hline Theme 2 & $\begin{array}{c}\text { Stakeholders are not aware of the need for university sustainability. } \\
\text { There is no demand for sustainability accounting and reporting by stakeholders. } \\
\text { The demand for university sustainability } \\
\text { accountability }\end{array}$ \\
$\begin{array}{c}\text { Source: Jones [2]; Lozano et al. [27]; Alonso-Almeida et al. [48]; Nejati et al. [21] } \\
\text { Theme 3 }\end{array}$ & $\begin{array}{l}\text { Universities are competing to be at the top of one green league table or another and } \\
\text { focusing on meeting ticked-box criteria on paper rather than the actual delivery of } \\
\text { sustainable development. } \\
\text { Source: Jones [50]; Jones [2] }\end{array}$ \\
\hline Theme 4 & $\begin{array}{l}\text { Unlike the financial dimension, the social and environmental dimensions have no } \\
\text { established mechanisms for measuring their delivery. } \\
\text { No agreed sustainability accounting standard. } \\
\text { Source: Lozano [26]; Lozano et al. [27]; Alonso-Almeida et al. [48] }\end{array}$ \\
\hline
\end{tabular}

"A weak theory of sustainability focuses on philanthropic or charitable contributions and activities, which the firm engages in as an adjunct to its business activities; any costs are weighed against the benefit to be gained in terms of the firm's enhanced reputation as a good corporate citizen" [51].

In social and environmental voluntary disclosure, legitimacy theory, institutional theory, stakeholder theory, and signalling theory are widely employed [31,41]. Legitimacy theory was derived from political economy theory and has been applied to explain organisational decisions about voluntary corporate social responsibility (CSR), sustainability reporting (SR), intellectual capital disclosure and Integrated Reporting [52,53]. The concept of legitimacy is directly related to the concept of a social contract. Organisations depend on an unwritten contract with their stakeholders and must be seen as legitimate in order to survive. In the Higher Education Institution sector, scholars have employed legitimacy theory to investigate voluntary disclosure practices. For example, Chatelian-Ponroy \& Morin-Delerm [54] argued that some universities adopted sustainable development and voluntary disclosure to obtain social approval. Taking a similar view, Ntim et al. [31] used legitimacy theory as a basis for their prediction that HEIs will increase their volun- 
tary disclosure in exchange for positive effects, e.g., institutional reputation, image, and public goodwill.

Taking into account that communication is the core function of universities, we are following the prior studies of Adhikariparajuli et al. [55] and adopting signalling theory in higher education. Signalling theory assumes that disclosure is costly, and organizations with proactive sustainability strategy have an incentive to provide extensive disclosure to signal their positive actions to stakeholders. In the context of higher education, signalling theory proposes that there is asymmetry of information which mostly favours universities [14]. This imbalance would ideally be a motivation for the university to publicly communicate and transmit helpful information to relevant stakeholders. Nevertheless, this natural rebalancing does not always occur as expected [14].

Based on our discussion in the previous section, we would expect that if universities reported on their integrated thinking activities, this would send positive signals to stakeholders on how universities create value for society. This, in turn, would be seen as an increase in the level of disclosure and would enhance their accountability and trust [56]. Furthermore, integrated thinking-as a tool for connectivity and interdependence between different departments-would eliminate the imbalance and clearly articulate the value created by the HEI sector [57]. The cause is simple: if managers are engaged in integrated thinking, universities can demonstrate interconnectivity between strategy, strategic objectives, risk and incentives, breaking down the barriers between departments and stimulating dialogue within different teams and contributing to holistic corporate reports [58].

\section{Research Methods and Data}

Data were collected via semi-structured interviews from a Scottish university. Participants were selected from the university's governing council, the Strategic Planning and Resources Group (SPARG), the estates' department, the transport department, the Centre for Understanding Sustainable Practice (CUSP), and the university's student union. These semi-structured interviews varied from participant to participant along with the roles and influence of each participant. Therefore, to unravel the realities of the sustainability accountability activities of the university, the research adopted a snowball approach to the conduct of the interviews, with each interview lasting about 20 to $30 \mathrm{~min}$. Figure 1 represents the processing of the interview data, from transcription to themes.

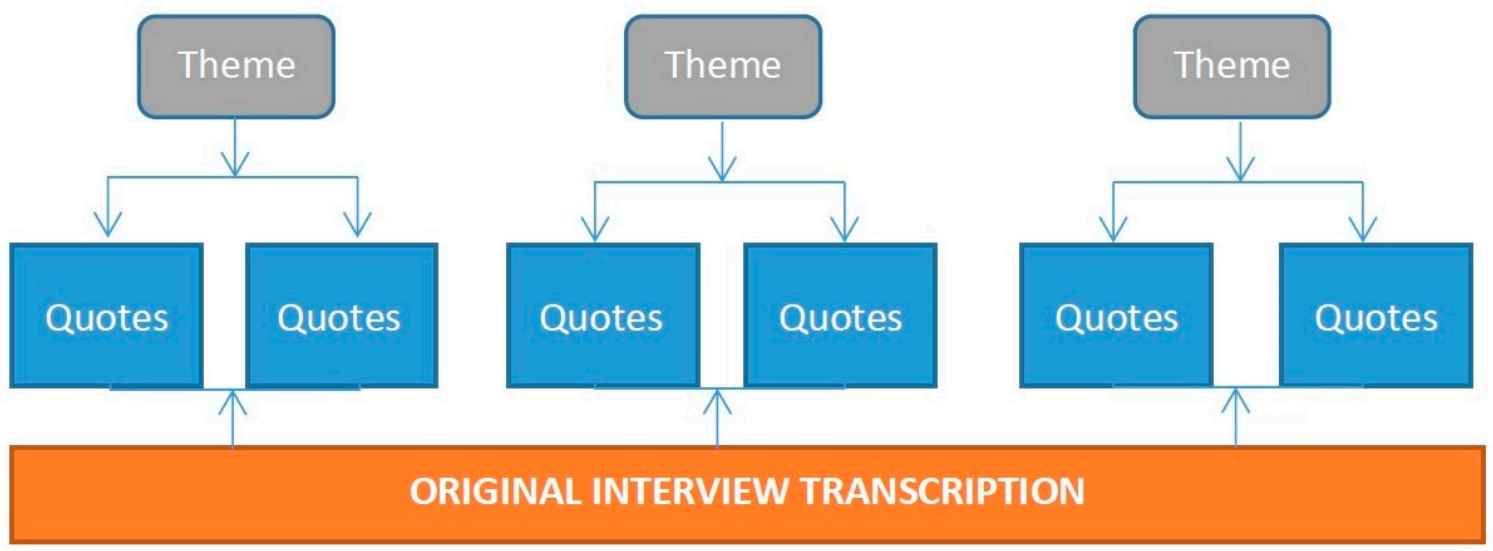

Figure 1. The hierarchical classification of respondents.

\subsection{Research Question Design}

In any credible research work that involves the adoption of primary data, the contextualization of the research question is of strategic importance [59]. The interview questions captured the central aims and focuses of the research study, which were considered in the conceptualization of the questions used for the process. Table 2 summarizes the categorization of interview questions. 
Table 2. Categorization of interview questions.

\begin{tabular}{|c|c|c|c|}
\hline Objective & Essential Questions & Extra Questions & Probing Questions \\
\hline $\begin{array}{l}\text { Objective } 1 \\
\text { Theme } 1 \\
\text { Definition of university } \\
\text { sustainability }\end{array}$ & $\begin{array}{l}\text { Q2: When did the university adopt sustainability as } \\
\text { a practice? } \\
\text { Q3: Is the university a signatory of/or certified to any } \\
\text { sustainability policy or agreement? } \\
\text { Q4: How integrated is sustainability into the strategic } \\
\text { plan of the university? }\end{array}$ & $\begin{array}{l}\text { Q1: What does the term 'university } \\
\text { sustainability' mean to you? } \\
\text { Q5: Is sustainability seen as a central } \\
\text { policy agenda to the university? If not, } \\
\text { why not? }\end{array}$ & $\begin{array}{l}\text { Q7: Who makes the decision on the sustainability } \\
\text { activities of the university? } \\
\text { Q15: The university's sustainability advisory group has } \\
\text { various committees, how are these committees } \\
\text { coordinated towards achieving a unified and } \\
\text { harmonious result? }\end{array}$ \\
\hline $\begin{array}{c}\text { Objective } 2 \\
\text { Theme } 2 \\
\text { The demand for university } \\
\text { sustainability and } \\
\text { accountability } \\
\text { Theme } 4 \\
\text { Mechanism for measuring } \\
\text { delivery }\end{array}$ & $\begin{array}{l}\text { Q6: Who are the real stakeholders of the university? } \\
\text { Q13: What is the level of stakeholder engagement } \\
\text { especially external representations such as the local } \\
\text { community in the strategy formulation and delivery of } \\
\text { sustainability in the university? } \\
\text { Q14: What is the relationship with strategic departments } \\
\text { such as; human resources with regards to recruitment } \\
\text { and estate management as it affects the general } \\
\text { wellbeing on campus? }\end{array}$ & $\begin{array}{l}\text { Q8: What does accountability mean } \\
\text { to you? }\end{array}$ & $\begin{array}{l}\text { Q9: What are the sustainability accounting and reporting } \\
\text { standards adopted by the university? }\end{array}$ \\
\hline $\begin{array}{c}\text { Objective } 3 \\
\text { Theme } 3 \\
\text { Competition and Competitive } \\
\text { rivalry } \\
\text { Theme } 4 \\
\text { Mechanism for measuring } \\
\text { delivery }\end{array}$ & $\begin{array}{l}\text { Q10: How is the university tracking the implementation } \\
\text { of sustainability accountability with its } \\
\text { various stakeholders? } \\
\text { Q12: What is the level of community outreach by } \\
\text { the university? }\end{array}$ & $\begin{array}{l}\text { Q11: What are the means of tracking } \\
\text { behavioral and cultural change } \\
\text { on campus? }\end{array}$ & $\begin{array}{l}\text { Q16: What is done to support research and development } \\
\text { in the area of sustainability in the university? }\end{array}$ \\
\hline
\end{tabular}




\subsection{Research Participants}

In presenting the findings of this study, various aspects that represent key components of the research findings have been categorized for a more concise understanding. The individual interviews carried out during the study were conceived strategically to cover the various relevant and active stakeholders in the policy formulation, strategy formulation, and day-to-day operations of the university. The individual participants represented the upper classification of the university's governing council, the Strategic Planning and Resources Group (SPARG), the sustainability advisory group, the Centre for Understanding Sustainable Practice (CUSP), the heads of various relevant departments, and the students (i.e., the student union). Figure 2 explains the hierarchical classification of respondents.

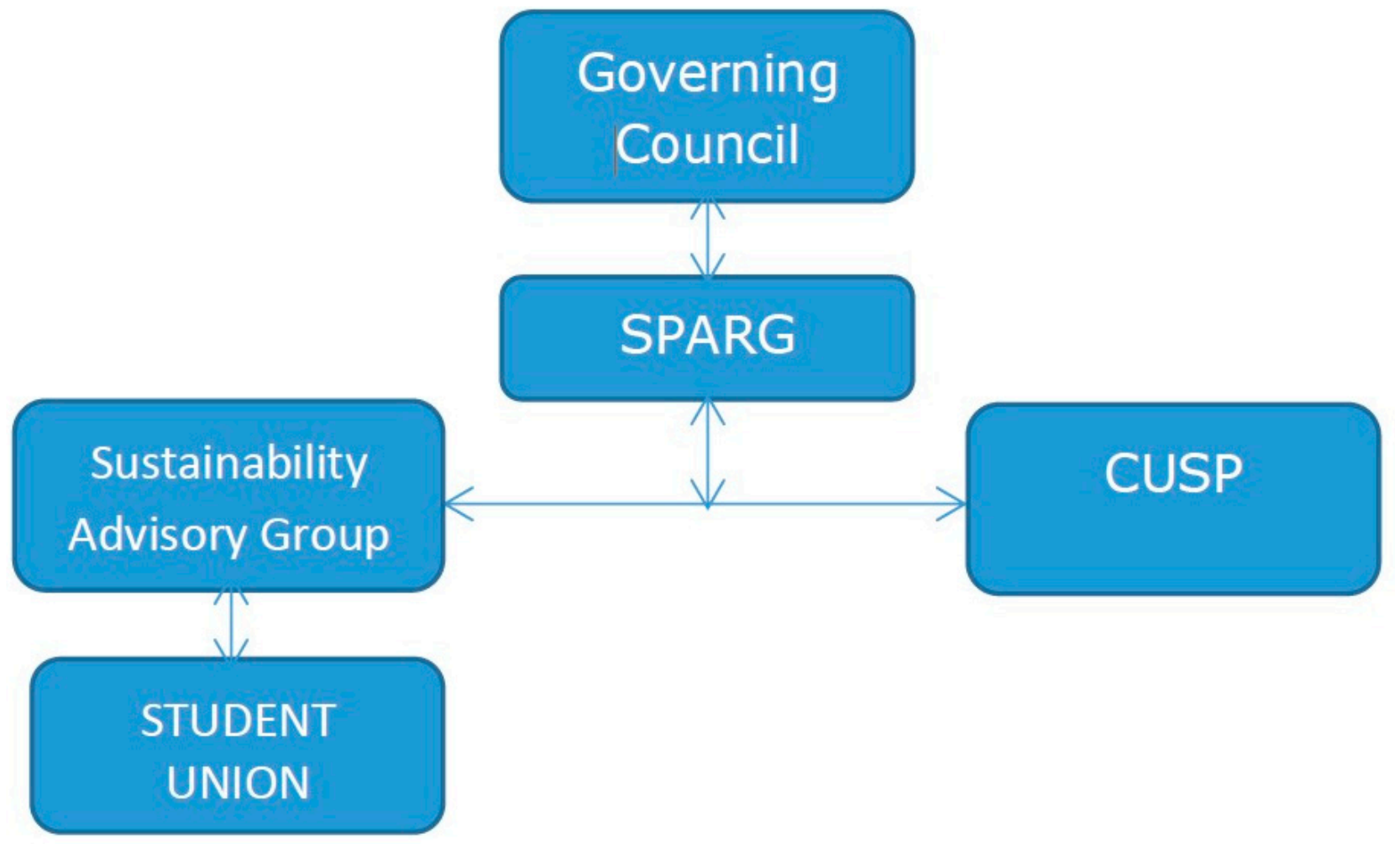

Figure 2. Hierarchical classification of respondents.

A total of twenty (20) respondents took part in the interviews. It is important to note, however, that, given the organizational structure of the university, a few of the respondents had overlapping functions. Table 3 summarizes the classification of interview participants.

Table 3. Classification of interview participants.

\begin{tabular}{cc}
\hline Classification & Number of Respondents \\
\hline The Governing Council & 3 \\
Management & 5 \\
Sustainability Advisory Group & 2 \\
Sustainability Centre & 3 \\
Student UNION & 7 \\
\hline
\end{tabular}

Source: Author.

\subsection{Data Analysis}

The research endeavoured to establish a case-oriented understanding of the findings, and then undertook analyses-primarily via the adoption of thematic analysis. However, narrative analysis was also adopted as a complementary means of analysing the qualitative 
data collected, in order to help strengthen the presentation of the findings and subsequently inform the conclusions drawn from said findings [60]. It was equally beneficial in comparing and exploring linkages and relationships within the various elements of each narrative account of the research subject for any possible benefit [59]. The inductive approach to qualitative data analysis was also adopted, as it establishes a set of procedures and processes to create substance from data via the establishments of categories and/or themes [61].

This stage involved the grouping and classification of qualitative data (gathered via interviews) into large groups based on theme classification and then further into sub-classes. The thematic classification of the parent group was based on terms that arose from within the data gathered. This was an inductive approach to qualitative research; no terminology was previously conceived, as doing so would have affected the context of the findings. Consequently, the parent themes encapsulated the research objectives, which were the overall essence of the study. The sub-themes covered any data that were of similar context or meaning and/or were related. The classification of the findings is presented in Figure 2.

The parent themes and related quotations set the tone for critical analyses of the research findings and the subsequent critical discussion in the research. The research only adopted reoccurring themes of sustainability and accountability as stated by respondents; the key attributes measured are represented in the classification of their responses. Saunders et al. [59] stated that the categorization of facts from interview transcripts required the combination of identified factors from the literature on various constructs measured because of the reoccurrence of related points from the respondents. Given the number of repetitions, the researchers decided to limit the categories to a number that effectively represented the identified themes and fit well within the scope of the research objectives.

\section{Findings and Discussion}

For this study, the interpretive research philosophy was adopted. The interpretive research philosophy endeavours to interpret existing facts rather than search for external causes [62]. The adoption of an interpretive approach assumes that the representation of societal realities is based on the observation of the researcher [63]. As such, the investigation into the state of sustainability accountability in Scottish universities-which is the focus of this study-represented not only the appreciation of theories, beliefs, and views of the society, but also the understanding of the values and actions of the concerned stakeholders. The research endeavoured to get to the underpinning realities of these sustainability initiatives, their effect on the university's stakeholders, and most importantly, the level of accountability of their sustainability practices.

Understanding the concept and reality of sustainability at the university-and by extension, Scottish universities, in general-required an understanding of the linkage between the reviewed literature and the empirical findings of the research. All of the interview respondents acknowledged that university sustainability was a rather new concept-as asserted by Lozano [26], Lozano et al. [27], Nejati et al. [21], and Jones [2,50]. The university had not conceptualized its definition of sustainability by simply adopted existing representations. However, there were varying definitions of sustainability by the respondents, indicating that there was no harmonious rhythm resonating at the university as per its sustainability agenda. Figure 3 presents the content.

It is very important to say that we are finalizing this paper while the world lives in the COVID-19 crisis. Since the announcement by the United Nations that they considered COVID-19 a pandemic, the higher education sector has played a vital role on both macro and micro levels [40]. On a macro level, medical schools have helped to manage the crisis by sending last-year medical students to help directly. Engineering schools designed personal protective plans for health workers. Many business schools at different universities have offered free webinars in areas such as crisis management, virtual work/telecommuting, and responsible business practices in order to help communities and businesses implement sustainability concepts. On a micro level, each university has tried their best to work closely 
with their IT departments to develop a reliable infrastructure that allowed continuous and timely communication with both staff and students. Institutions faced an unprecedented challenge- the sudden move to online education - which required leadership, creativity, agility, and cooperation in order to reinvent education delivery and implement virtual campus operations. This, in our own opinion, is the heart of sustainability.

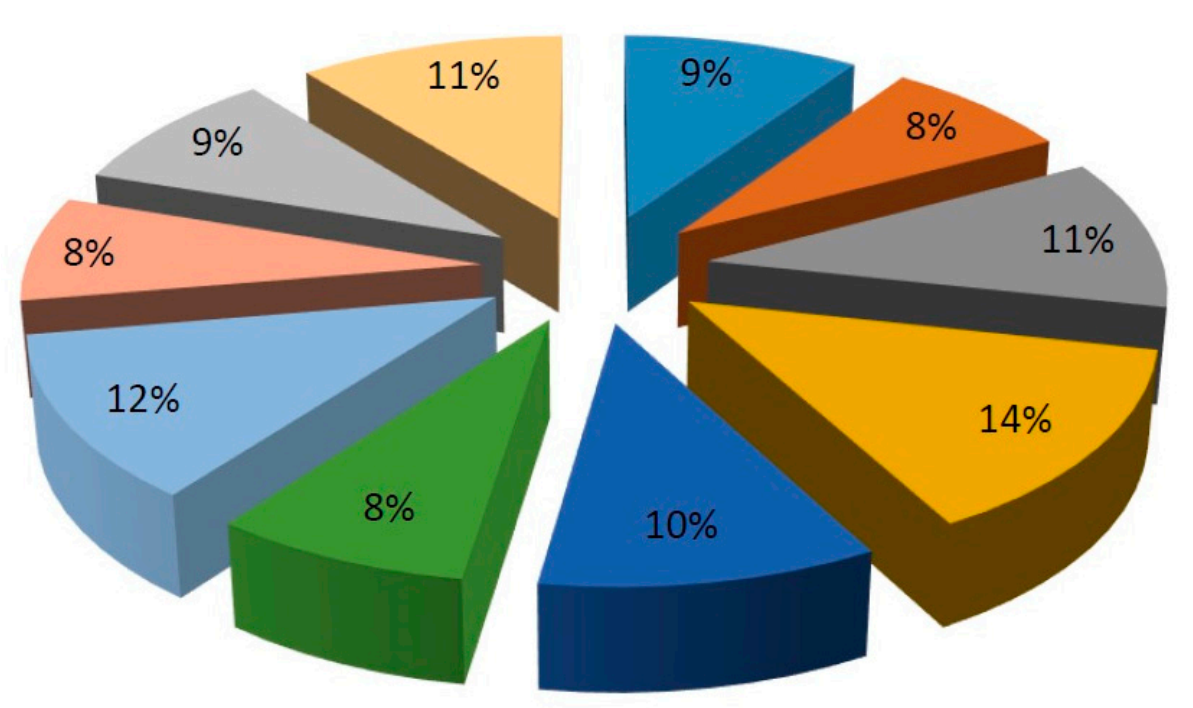

Figure 3. Representation of content analysis.

\author{
Building \\ Carbon \\ Community \\ Energy \\ Environmental \\ Planning \\ Report \\ Responsibility \\ Staff
}

\section{Students}

\subsection{Theme 1: Definition of University Sustainability}

The definition of sustainability has been quite controversial over the years [64]. All of the interview respondents perceived sustainability in an environmental context. This was in contrast to the university's leadership, who prioritized sustainability in an economic context. Lozano [26] asserted that a major concern around university sustainability is that narrow view of university sustainability-focusing on environmental and economic dimensions alone, leaving out social and educational contexts. The school leadership described university sustainability as ensuring that there was adequate funding to ensure the long-term existence of the university.

Governing Council: "a framework of financial planning which ensures that it can meet its obligations and also to secure its strategic targets over a medium to long term".

The university leadership's perception of sustainability will affect focus and delivery. Because the university operates in a top-down fashion, there is a need for a robust definition of sustainability (in the context of the strategic long-term focus of the university). The governing council are strategically positioned to monitor and demand compliance with good governance standards [31]. In this instance, the integrated thinking approach will be very useful for all the organization units/departments.

As evident in Figure 3 above, the term energy enjoyed the highest degree of reoccurrence $(14 \%)$. Energy, in this context, referred to the strategic goal of the university to substantially reduce energy costs over time. This complemented its objective of ensuring financial sustainability. In contrast, carbon enjoyed the lowest level of reoccurrence, which indicated that the context of energy identified earlier has more to do with cost than carbon reduction.

Sustainability was not perceived as a major responsibility by the leadership of the university. This was reflected in the views of the respondents; they asserted that the university managed sustainability within the ambit of its legal requirements, and not as a strategy for growth and development in its day-to-day dealings. The consequences of 
this were revealed by one of the respondents. It was made clear that the university has been ranked poorly by the 'People and Planet' sustainability league table amongst other universities in the United Kingdom.

Sustainability Center: "The first year it was done, the university came I think 110 out of about 120. And $x \times x \times x$ was horrified, but to me that was realistic. That's where we belonged given what we do and how we behave as an institution".

\subsection{Theme 2: Demand for Sustainability Accountability}

Recent studies have either concentrated primarily on the effects of voluntary disclosure on general institutional characteristics or have been mostly analytical with minimal theoretical perspectives [65]. However, the findings of this study showed that there was little sustainability consciousness amongst the university stakeholders, and that the level of awareness of the university's sustainability initiative was very low. Therefore, more attention is needed in the area of voluntary disclosure by HEIs to their stakeholders [66].

A respondent, stating realities from the perspective of the transport department whilst responding to the question of 'how the university tracked the implementation of sustainability accountability' asserted that, "from a transport point of view its surveys, I suppose from an energy point of view it is accounting and bills." This indicated clearly that little has been done to engage the various stakeholders in any form of discourse on the sustainability initiatives of the university.

There have been increasing analytical and theoretical suggestions that institutional decisions on disclosure-including governance decisions-are largely affected by the composition of top management teams [67]. Current research exploring the effects of internal governance systems on voluntary disclosures in HEIs are uncommon [31,66,68]. A major factor that affects the delivery of sustainability is a dormant stakeholder group [68]. The lack of sustainability consciousness by the students and staff of the university has been a major barrier hindering the growth of sustainability at the university. In addition, more disclosure would be in line with signalling theory assumptions.

In contrast, the university's student union has taken the lead role in the actualization of more awareness amongst different stakeholder groups. However, as evident in Figure 3, the occurrence of students $(11 \%)$ in the content analysis was very similar to staff $(11 \%)$. The respondent representing the union averred that although the sustainability committee of the union was in infancy, raising awareness amongst the student populace was a major priority.

Student Union: "Actually we have few programs that are funded through the climate challenge fund which are very much aimed at behavioural changes mixed with a bit of education".

The university, therefore, needs to roll out awareness campaign concepts to ensure that there is adequate awareness amongst its stakeholders, as this is critical for the actualization of its sustainability objectives. On a different note, there is an equal need to reframe sustainability as a competitive advantage. The emerging realities of today's global business environment have demonstrated a growing call for accountability and transparency about sustainability by established institutions.

As asserted by Lozano et al. [27], the social and educational dimensions of university sustainability should enjoy equal priority in the focus of universities. The educational dimension can help create the awareness required to properly integrate the stakeholders into the delivery of sustainability in universities.

\subsection{Theme 3: Competition and Competitive Rivalry}

The growing significance of sustainability in recent years has resulted in the development of specialized models to accurately assess sustainable competitiveness at different levels. Unfortunately, none has been specifically developed for HEIs [69]. A few examples of these models are: the Climate Change Performance Index, the Environmental Sustainability Index, the Global Destination Sustainability Index, Sustainable Economic Welfare, 
the Environmental Performance Index, the Sustainable Cities Index, the Global Green Economy Index, and the Global Sustainable Competitiveness Index. Competition among higher institutions is evidenced by the development of healthy campuses $[69,70]$. However, Jones [2] expressed a major dissatisfaction at the manner in which this competitiveness is exhibited by universities; he opined that the greenwashing approach adopted by universities in their bid to attain the topmost position in one green league table or another is a charade, rather than a true reflection of the university's sustainability commitment. During this study, research found this assertion to be realistic. One of the respondents revealed that, after the initial 'People and Planet' green league ranking that saw the university claim the 110th position out of 120 universities, there was a call for improvement by school management. The respondent further stated that afterward, the sustainability advisory group contextualized a sustainability framework to better position the university and improve its rankings on the league table, which led to the rise of the university to 60th place. However, the respondent expressed dissatisfaction at the fact that the university simply represented these facts and figures on paper, otherwise doing little or nothing to improve its practices.

Advisory Group: "for 2 years myself and '????' took a lot of the universities information and rewrote it, and optimized it and made the most of it; and I think we got the university as far as about 60th place in the league".

The unhealthy spirit of competitiveness expressed by the university soon saw it decline to the 122nd position, according to the respondent.

The desire of universities to stay ahead of and atop their competition must be reflected in day-to-day activities and operations. Sustainability should be critical to their competitive advantage and the various league tables need to carry out thorough investigations into the sustainability activities of these universities, rather than just submitting forms full of boxes for them to tick, as asserted by Jones [2]. The spate of greenwashing should be nipped in the bud. Failure to do so could have dire consequences on the future of these universities.

The above results are in line with our suggestion that the provision of this relevant information can lead to better communication between the organization and its stakeholders, supporting a signalling theory interpretation [14]. Therefore, we are suggesting that integrated thinking is an internal process that organizations can follow to increase the level of disclosure as a communication tool with stakeholders.

\subsection{Theme 4: Mechanisms for Measuring Delivery}

As identified by all the respondents, the university did not have a particular mechanism for measuring sustainability initiatives. Various departments had to conceptualize internal mechanisms for measuring their activities. The school leadership said it was obligated under the carbon reduction commitment (CRC) to reduce its carbon emission by forty percent $(40 \%)$ by 2020 . This was a statutory requirement by the government on all universities, indicating that the university had no particular internal target of its own toward which to work.

However, as a reflection of the university's strong economic focus, the leadership of the university-responding to questions on the mechanisms put in place to measure the delivery of sustainability-asserted that:

Management: "There are financial reporting standards; there is a financial memorandum which is an agreement between the university and the funding council which will set aside how we spend public money and how we report to the funding council on that public money".

The findings of the study indicated that there was no attention paid to the educational context, as asserted by Lozano [26], or, if there were, that it was intangible. Although researchers like Hess [44] identified that there was no universally adopted sustainability accounting framework for universities, Lozano et al. [27] proposed that the Global Reporting Initiative (GRI) should be modified to contextualize the educational dimension of 
sustainability and consequently be adopted as the universal standard for measuring and reporting on university sustainability. The actualization of this, however, might take a long time. Given that the social, environmental, and educational dimensions of sustainability are as difficult to quantify as the economic dimension, adjudging sustainability performance in universities might be a difficult nut to crack.

\section{Conclusions}

In line with the reflection of the research exercise presented above, it is evident that the state of sustainability accountability in Scottish universities has been established. This research paper clearly articulated the research journey. The research identified and reviewed relevant literature in a bid to set the tone for the primary research exercise. This paper equally established the adoption of the most appropriate methodologies and methods in the conduct of the research, thereby ensuring the credibility, reliability, and validity of the research findings in line with the required ethical code of conduct.

The findings of this research exercise clearly showed that the research problem identified at the commencement of this project was reflective of the findings of the qualitative data gathered. The choice of an inductive approach ensured that the findings of the research were conceived with no preconceptions. The adoption of two qualitative data analysis techniques reflected the effort to ensure that findings were critically analysed and discussed. From the critical analysis and discussion presented, it was evident that the state of sustainability and sustainability accountability at the university was weak. As presented in previous literature, the university had no holistic framework guiding its sustainability agenda. The university simply ensures that it stayed within the statutory requirements of the regulatory body and the requirements of law. This practice of sustainability has been condemned by previous research because it lacks in proper representation of the various dimensions of sustainability, e.g., the educational, economic, social, and environmental dimensions.

Consequently, the research findings indicated that the university prioritized only two sustainability dimensions: economic and environmental. The attention enjoyed by the economic dimension (as stated by the university's leadership) stems from the statutory requirement for the funding council to present a report on financial activities. In a similar vein, the environmental focus was reflective of a statutory requirement to operate within certain environmental standards. This requirement is not peculiar to the university-every university in Scotland has the same responsibility. Evidence gathered showed that universities still perceive sustainability as a voluntary exercise. It is surprising, however, that universities (the bedrock of education) are lagging in their sustainability responsibilities. The findings clearly indicated that, while sustainability enjoyed sizeable attention at the university, it has yet to be identified and adopted as a central policy in the formulation of university strategy. The findings further revealed that the university has no unified sustainability direction, as different respondents gave varied accounts of the sustainability focus of the university. Our results also indicated that the provision of relevant information about sustainability would lead to better communication between the organization and its stakeholders. This supported a signalling theory interpretation and justified integrated thinking as an internal process that organizations should adopt as a communication tool in order to increase the level of disclosure to their stakeholders. From our study, it became evident that there was scant synergy of ideas and direction between the Sustainability Advisory Group and the Centre for the Understanding of Sustainable Practice (CUSP). However, we expect that this will change as a reflection of integrated thinking-especially due to the recent COVID-19 crisis, which has made it evident that collaboration between all stakeholders is the solution to many problems.

It was evident that the university had no framework in place for measuring sustainability delivery, and therefore had no established medium for communicating these activities to its stakeholders. This was also born out of the fact that the university stakeholders are dormant, as most of the staff and students are unaware of the university's sustainability 
activities. The research sees this as a major cause for concern, as feedback is necessary for improvement, learning, and growth. Consequently, the research findings showed that the social and educational contexts of sustainability were lacking at the university. The university has done little or nothing to educate its stakeholders on sustainability. There was also no mechanism put in place to track and monitor behavioural and attitudinal changes among its stakeholders. Although the university established and rendered social services-e.g., health care delivery, sport and gym facilities, day-care services-to the community, there was no external stakeholder input in sustainability policy formulation. Furthermore, the findings revealed that the university's student union body prioritized sustainability and sustainable development more than the university itself. The union has endeavoured to educate and enlighten the student population, and took the initiative of employing a sustainability team to ensure that adequate attention was paid to sustainability development.

In conclusion, the research scored the university quite low on sustainability activities and commitment. The university's sustainability initiatives lacked direction and focus. The university needs to conceptualize a robust sustainability framework that will consider all the facets of sustainability and deliver true accountability of its activities to its stakeholders.

\section{Areas for Further Research}

Given the limitations of this research - both in terms of scope and in terms of available resources-there is a need for further research on better delivery of sustainability by universities. This research exercise focused solely on the stakeholders relevant to the implementation of sustainability at the university. However, there is a need for more well-rounded research that will take into account the views of university students and staff along with the views and opinions of external stakeholders. Comparative research is necessary to compare the sustainability focus of various universities in a bid to better understand the underpinning sustainability realities across different cultures.

Finally, future research should endeavour to unravel the role and influence of culture on the effective delivery of sustainability in universities. This will be relevant and help researchers to better understand the social dimensions of university sustainability. Given that this research project and past research have identified the lack of accountability as a major lag in the delivery of sustainability initiatives.

Author Contributions: Writing—original draft, A.R.; Writing—review \& editing, A.H. Both authors have read and agreed to the published version of the manuscript.

Funding: This research received no external funding.

Institutional Review Board Statement: Not applicable.

Informed Consent Statement: Not applicable.

Data Availability Statement: Not applicable.

Conflicts of Interest: The authors declare no conflict of interest.

\section{References}

1. Yáñez, S.; Uruburu, Á.; Moreno, A.; Lumbreras, J. The sustainability report as an essential tool for the holistic and strategic vision of higher education institutions. J. Clean. Prod. 2019, 207, 57-66. [CrossRef]

2. Jones, D.R. Looking through the "greenwashing glass cage" of the green league table towards the sustainability challenge for UK universities. J. Organ. Chang. Manag. 2012, 25, 630-647. [CrossRef]

3. Muijen, H.S.C.A. Corporate Social Responsibility Starts at University. J. Bus. Ethics 2004, 53, 235-246.

4. Puertas, R.; Marti, L. Sustainability in Universities: DEA-GreenMetric. Sustainability 2019, 11, 3766. [CrossRef]

5. Wright, T.S. Developing research priorities with a cohort of higher education for sustainability experts. Int. J. Sustain. High. Educ. 2007, 8, 34-43. [CrossRef]

6. Asemah, E.S.; Gujbawu, M.; Ekhareafo, D.O.; Okpanachi, R.A. Research methods and procedures in mass communication. Int. Multidiscip. J. 2013, 7, 195-224.

7. Teslenko, T. Engaging Students and Campus Community in Sustainability Activities in a Major Canadian University. In World Sustainability Series; Springer International Publishing: New York, NY, USA, 2019; pp. 3-20. 
8. Mcwilliams, A.; Siegel, D. Corporate Social Responsibility: A Theory of the Firm Perspective. Acad. Manag. Rev. 2001, 26, 117-127. [CrossRef]

9. Cheeseman, A.; Wright, T.S.A.; Murray, J.; McKenzie, M. Taking stock of sustainability in higher education: A review of the policy literature. Env. Educ. Res. 2019, 25, 1697-1712. [CrossRef]

10. Mcwilliams, A.; Siegel, D. Corporate social responsibility and financial performance: Correlation or misspecification? Strat. Manag. J. 2000, 21, 603-609. [CrossRef]

11. Smith, A.D. Making the case for the competitive advantage of corporate social responsibility. Bus. Strat. Ser. 2007, 8, 186-195. [CrossRef]

12. Moggi, S. Social and environmental reports at universities: A Habermasian view on their evolution. Account. Forum 2019, 43, 283-326. [CrossRef]

13. BUFDG. Phase 2 Report on Integrated Reporting is Published. 2017. Available online: https://www.bufdg.ac.uk/resources/ news /view?g=6f0aebb3-9fb6-4f58-9a48-670726e5b409\&t=Phase \%202\%20report $\% 20$ on \%20Integrated $\% 20$ Reporting $\% 20$ is $\% 20$ published (accessed on 10 March 2021).

14. Zutshi, A.; Creed, A. Declaring Talloires: Profile of sustainability communications in Australian signatory universities. J. Clean. Prod. 2018, 187, 687-698. [CrossRef]

15. Hayter, C.S.; Cahoy, D.R. Toward a strategic view of higher education social responsibilities: A dynamic capabilities approach. Strat. Organ. 2016, 16, 12-34. [CrossRef]

16. Ralph, M.; Stubbs, W. Integrating environmental sustainability into universities. High. Educ. 2014, 67, 71-90. [CrossRef]

17. Nejati, M.; Nejati, M. Assessment of sustainable university factors from the perspective of university students. J. Clean. Prod. 2013, 48, 101-107. [CrossRef]

18. Vukasovic, M. The integrity of higher education from essence to management. In Proceedings of the Seminar of the Magna Charta Observatory, Bologna, Italy, 10 September 2008.

19. Adams, C.A.; Mcnicholas, P. Making a difference: Sustainability reporting, accountability and organizational change. Account. Audit. Account. J. 2007, 20, 382-402. [CrossRef]

20. Wright, T. University presidents' conceptualizations of sustainability in higher education. Int. J. Sustain. High. Educ. 2010, 11, 61-73. [CrossRef]

21. Nejati, M.; Shafaei, A.; Salamzadeh, Y.; Daraei, M. Corporate social responsibility and universities: A study of top 10 world universities' websites. Afr. J. Bus. Manag. 2011, 5, 440-447.

22. Shattock, M. University governance in flux. The impact of external and internal pressures on the distribution of authority within British universities: A synoptic view. High. Educ. Q. 2017, 71, 384-395. [CrossRef]

23. Higher Education Funding Council for England, Funding Higher Education in England: How the HEFCE Allocates its Funds. 2002. Available online: www.hefce.ac.uk/research/rfund02.htm (accessed on 10 March 2021).

24. Vargas, V.R.; Lawthom, R.; Prowse, A.; Randles, S.; Tzoulas, K. Sustainable development stakeholder networks for organisational change in higher education institutions: A case study from the UK. J. Clean. Prod. 2019, 208, 470-478. [CrossRef]

25. Schulze-Cleven, T.; Olson, J.R. Worlds of higher education transformed: Toward varieties of academic capitalism. High. Educ. 2017, 73, 813-831. [CrossRef]

26. Lozano, R. Diffusion of sustainable development in universities' curricula: An empirical example from Cardiff University. J. Clean. Prod. 2010, 18, 637-644. [CrossRef]

27. Lozano, R.; Llobet, J.; Tideswell, G. Developing a University Sustainability Report: Experiences from the University of Leeds. In Sustainability Assessment Tools in Higher Education Institutions; Springer: New York, NY, USA, 2013; pp. $189-203$.

28. Lozano, R. The state of sustainability reporting in universities. Int. J. Sustain. High. Educ. 2011, 12, 67-78. [CrossRef]

29. Hinson, R.; Gyabea, A.; Ibrahim, M. Sustainability reporting among Ghaiain universities. S. Afr. J. Commun. Theory Res. 2015, 41, 22-42.

30. Vagnoni, E.; Cavicchi, C. An explanatory study of sustainable development at Italian universities. Int. J. Sustain. High. Educ. 2015, 16, 217-236. [CrossRef]

31. Ntim, C.G.; Soobaroyen, T.; Broad, M.J. Governance structures, voluntary disclosures and public accountability. Acc. Audit. Acc. J. 2017, 30, 65-118. [CrossRef]

32. Milne, M.J.; Gray, R.W. The triple bottom line, the global reporting initiative, and corporate sustainability reporting. J. Bus. Ethics 2012, 118, 13-29. [CrossRef]

33. Norman, W.; Macdonald, C. Getting to the bottom of "triple bottom line". Bus. Ethicsq. 2004, 14, 243-262. [CrossRef]

34. Shi, H.; Lai, E. An alternative university sustainability rating framework with a structured criteria tree. J. Clean. Prod. 2013, 61, 59-69. [CrossRef]

35. Bekessy, S.A.; Samson, K.; Clarkson, R.E. The failure of non-binding declarations to achieve university sustainability: A need for accountability. Int. J. Sustain. High. Educ. 2007, 8, 301-316. [CrossRef]

36. Filho, J.M.D.S.; Wanderley, L.S.O.; Gómez, C.P.; Farache, F. Strategic corporate social responsibility management for competitive advantage. Bar. Braz. Adm. Rev. 2010, 7, 294-309. [CrossRef]

37. Deegan, C. The legitimizing effect of social and environmental disclosures: A theoretical foundation. Account. Audit Account. J. 2002, 15, 282-311. [CrossRef] 
38. Sepasi, S.; Braendle, U.; Rahdari, A.H. Comprehensive sustainability reporting in higher education institutions. Soc. Responsib. J. 2019, 15, 155-170. [CrossRef]

39. Kolk, A. Sustainability, accountability and corporate governance: Exploring multinationals' reporting practices. Bus. Strat. Environ. 2007, 17, 1-15. [CrossRef]

40. Hassan, A. Integrated Thinking on Macro and Micro Levels in UK HEIs During the Covid-19 Crisis Insights from the University of the West of Scotland (UWS). 2020. Available online: https:/ / www.advance-he.ac.uk/news-and-views/all-together (accessed on 22 December 2020).

41. Hassan, A.; Adhikariparajuli, M.; Fletcher, M.; Elamer, A. Integrated reporting in UK higher education institutions. Sustain. Acc. Manag. Policy J. 2019, 10, 844-876. [CrossRef]

42. KING REPORT IV. Corporate Governance for South Africa 2016. Available online: www.oidsa.co.za/resource/resmgr/king/_iv_ Report/IoDSA_King_IV_Report_-_WebVe.pdf (accessed on 10 March 2021).

43. IIRC. The Integrated Reporting Framework. 2013. Available online: https://integratedreporting.org/resource/international-irframework/ (accessed on 10 March 2021).

44. Hess, D. The future of sustainability reporting as a regulatory mechanism. In Law and the Transition to Business Sustainability; Springer: Cham, Switzerland, 2014; pp. 125-139.

45. Adhikariparajuli, M.; Hassan, A.; Siboni, B. CSR Implication and Disclosure in Higher Education: Uncovered Points. Results from a Systematic Literature Review and Agenda for Future Research. Sustainability 2021, 13, 525. [CrossRef]

46. Biondi, L.; Bracci, E. Sustainability, Popular and Integrated Reporting in the Public Sector: A Fad and Fashion Perspective. Sustainability 2018, 10, 3112. [CrossRef]

47. Chiba, S.; Talbot, D.; Boiral, O. Sustainability adrift: An evaluation of the credibility of sustainability information disclosed by public organizations. In Accounting Forum; No Longer Published by Elsevier; Elsevier: Amsterdam, The Netherlands, 2018; Volume 42, pp. 328-340.

48. Alonso-Almeida, M.D.M.; Marimon, F.; Casani, F.; Rodriguez-Pomeda, J. Diffusion of sustainability reporting in universities: Current situation and future perspectives. J. Clean. Prod. 2015, 106, 144-154. [CrossRef]

49. Bufdg, Progress on Latest Project. Available online: https://www.bufdg.ac.uk/resources/news/view?g=202eb51d-0903-4c1c-b3 ab-9e2f1e27e7f9 (accessed on 10 March 2021).

50. Jones, D.R. University Sustainability League Tables. Greener Manag. Int. 2007, 2007, 104-131. [CrossRef]

51. Freeman, R.E. Strategic Management: A Stakeholder Approach; Pitman Publishing: Boston, MA, USA, 1984.

52. Guthrie, J.; Manes-Rossi, F.; Orelli, R.L. Integrated reporting and integrated thinking in Italian public sector organisations. Meditari Account. Res. 2017, 25, 553-573. [CrossRef]

53. Savage, A.; Gilbert, E.; Rowlands, J.; Cataldo, A.J. Environmental disclosure in annual reports: A legitimacy theory perspective. S. Afr. J. Acc. Res. 2001, 15, 19-48.

54. Chatelain-Ponroy, S.; Morin-Delerm, S. Adoption of sustainable development reporting by universities: An analysis of French first-time reporters. Account. Audit. Account. J. 2016, 29, 887-918. [CrossRef]

55. Adhikariparajuli, M.; Hassan, A.; Fletcher, M.; Elamer, A.A. Integrated reporting in higher education Insights from Scotland, Northern Ireland and Wales. Soc. Responsib. J. 2020. [CrossRef]

56. Rinaldi, L.; Unerman, J.; De Villiers, C. Evaluating the integrated reporting journey: Insights, gaps and agendas for future research. Account. Audit. Acc. J. 2018, 31, 1294-1318. [CrossRef]

57. Adams, C.A. Debate: Integrated reporting and accounting for sustainable development across generations by universities. Public Money Manag. 2018, 38, 332-334. [CrossRef]

58. Stacchezzini, R.; Florio, C.; Sproviero, A.F.; Corbella, S. An intellectual capital ontology in an integrated reporting context. J. Intellect. Cap. 2019, 20, 83-99. [CrossRef]

59. Saunders, M.; Lewis, P.; Thornhill, A. Research Methods for Business Students, 4th ed.; Pearson Education Limited: New York, NY, USA, 2007.

60. Morse, J.M. Critical Issues in Qualitative Research Methods; Sage Publications, Inc.: Thousand Oaks, CA, USA, 1994.

61. Thomas, D.R. A General Inductive Approach for Analyzing Qualitative Evaluation Data. Am. J. Eval. 2006, 27, 237-246. [CrossRef]

62. Collis, J.; Hussey, R. Business Research: A Practical Guide for Undergraduate and Postgraduate Students, 3rd ed.; Palgrave Macmillan: New York, NY, USA, 2009.

63. Crossan, F. Research philosophy: Towards an understanding. Nurse Res. (Through 2013) 2003, 11, 46. [CrossRef]

64. Carroll, A.B. The pyramid of corporate social responsibility: Toward the moral management of organizational stakeholders. Bus. Horiz. 1991, 34, 39-48. [CrossRef]

65. Coy, D.; Dixon, K. The public accountability index: Crafting a parametric disclosure index for annual reports. Br. Account. Rev. 2004, 36, 79-106. [CrossRef]

66. Sassen, R.; Azizi, L. Voluntary disclosure of sustainability reports by Canadian universities. J. Bus. Econ. 2017, 88, 97-137. [CrossRef]

67. Beekes, W.; Brown, P. Do better-governed Australian firms make more informative disclosures? J. Bus. Financ. Account. 2006, 33, 422-450. [CrossRef]

68. Gordon, T.; Fischer, M.; Malone, D.; Tower, G. A comparative empirical examination of extent of disclosure by private and public colleges and universities in the United States. J. Account. Public Policy 2002, 21, 235-275. [CrossRef] 
69. Okanović, A.; Ješić, J.; Đaković, V.; Vukadinović, S.; Panić, A.A. Increasing University Competitiveness through Assessment of Green Content in Curriculum and Eco-Labeling in Higher Education. Sustainability 2021, 13, 712. [CrossRef]

70. Ting, J.K.S.; Tan, V.M.; Voon, M.L. Factors Influencing Student Engagement in Higher Education Institutions: Central to Sustainability and Progression of the Institution. Eur. J. Mol. Clin. Med. 2020, 7, 449-452. 